\title{
SPECIAL CORRESPONDENCE.
}

Treatment of Blepharospasm.

To the Editor:-In the last number of THE JoURNAI, (December 27, I890), under the heading of "Treatment of Blepharospasm," Giraud, (Thése de Paris) is quoted as treating this annoying and at times intractable affection by forcible dilatation, using a pair of retractors or a spring speculum-the separation of the lids being carried to a degree of exposing the conjunctival culde-sac-and keeping the eyelids in this position for three or four minutes. For several years I have been using a similar method in my clinic at the New York Fye and Far Infirmary - with the difference that I do not forcibly put the orbicularis palpebrarum on the stretch. The good results, not from stretching, but from the exposure of the sensitive cornea to daylight - the natural stimulus of the eye. In all cases of conjunctival or corneal trouble this procedure cures the blepharospasm if it exists. The speculum is put between the eyelids and opened so as to expose the cornea. Patient is kept with the eye exposed to diffuse daylight from five to ten minutes. I find that most of the cases occur in children and are due to phlyctenular keratitis. In many of the cases the photophobia is very great, and the children avoid light with might and main. The little sufferer buries its face in the pillow or the mother's breast. With this condition existing for a few weeks-the room darkened, perhaps-it is easy enough to imagine how a blepharospasm comes on. If the child is placed in an upright position or put on its back, the chances are that it will begin to sneeze. This is due to the change in temperature that takes place in the nose. When the head is buried in the breast or pillow the nose is kept unduly warm by the breath, but on changing from the bent position, so that the breath does not unduly heat the nose, the sneezing begins, the slight change in temperature is sufficient. In this connection I may add that it is not the light which causes the child to sneeze, as some suppose.

With regard to the suggestion of using an eye speculum in blepharospasm, the credit, if I am not mistaken, belongs to the late Dr. C. R. Agnew. Very truly,

New York, December 29, I8go.

\section{Peter A. Callan, M.D.}

\section{Sha11 The Journal be Removed to Washington?}

To the Editor:-I cannot see any valid reason for changing the locality of publication of THE JOURNAL. If at any time it could be shown that the interest of THE JOURNAL and of the members of the Association would be enhanced, then I am ready to coöperate with the members in such action. It seems to me removal to Louisville, Cincinnati or New York would be just as good as Washington. Facilities of mail are such that subscribers will receive THE JOURNAL, within a few hours as soon from Chicago as any other point.

Harkers Corners, Ill., Jan. ${ }_{3} 3$, I891. N. Holton, M.D.

To the Editor:-By all means do not remove THE Journal office. Chicago I consider by odds the very best place for the office for several splendid reasons; the first I consider enough - "that it is so easy of access from any part of the United States." I also think that there are a good many other good reasons in favor of Chicago, but do think this one enough, especially when compared with Washington, which place I think has no good reason in favor of such a removal.

Topeka, Kan., Jan. II, I89I. H, K. TEFF', M.D.

To the Editor:-I am opposed to the proposition made to move the publication office and management of THE JOURNAL of the Association to Washington City. I vote CHICAGO to be continued as its permanent home because it is most central and has unexcelled mail facilities to all parts of the country, and because it is now and will continue to be nearer the centre of population, and destined to be the greatest medical centre of the United States.

I would formulate a ballot and distribute to every member of the Association, requesting his vote on location, with signature and $P$. O. address, to be returned to the committee having the question of location in charge. This seems to be the legitimate way to satisfactorily settle the issue. W. W. Hester, M.D. 3640 Cottage Grove Ave., Chicago, Jan. 16, I89I.

To the Editor:-While there appear so many reasons for keeping THE Journal where it is, I oppose the question of removal. It would seem that the facility of distribution which the present location affords should decide the matter if nothing else does.

I second Dr. Dimmitt's motion that a vote be taken at an early date. This will give every member a chance to express his opinion. W. E. WARD, M.D.

255 North ave., Chicago, Ill., Jan. I7, I89I.

To the Editor:-I am opposed to moving THE JoURNAL to Washington or any other city. The suggestion of Dr. Dimmitt's (January 17) is a good one.

Springfield, Ill., Jan. I9, I89I.

To the Editor:-There is no city in the United 